American Journal of Agricultural and Biological Sciences 4 (1): 12-17, 2009

ISSN 1557-4989

(C) 2009 Science Publications

\title{
High Quality Komatsuna (Brassica rapa L. nothovar) Production by Using Silicate Minerals Treated Nutrient Solution
}

\author{
Sheheli Islam, Kumagai Kazunori, Noriko Takeda and Katsumi Ishikawa \\ Lab of Biological and Environmental Systems, \\ Kochi University, Nankokushi, Monobe B 200, Kochi 783-8502, Japan
}

\begin{abstract}
Problem statement: Good water quality not only produces good crop yield, but also maintains environmental quality and so with plant, animal and human health. Therefore, protecting the quality of water by using non chemical materials is an emerging issue to be solved. Bakuhan seki having additional negative charge were found to have the capacity of improving condition of water while emitting important minerals essential to life. Because of high cost and scarcity of Bakuhan-seki, experiments continued to find out low cost materials. In this study, a very timely and relevant and costefficient procedure has been described for determining the potential of three minerals of Shikoku Island to improve water quality affecting growth of plants. Approach: Firstly, tap water of Kochi, Japan was treated with different mixtures of silicate minerals and then applied for the germination of Komatsuna (Brassica rapa L. nothovar) seeds. The feasibility of these treatments was investigated by measuring root and shoot length of early seedlings. Results: Treatment with Q4S1 showed the highest elongation of seedling parameters compared to other treatments. Where as results of growth tests using Komatsuna in the NFT (Nutrient Film Technique) system, showed degree of leaf freshness (SPAD) and dry matter contents were higher than controls. Also amount of $\mathrm{K}$ and $\mathrm{Mg}$ was found higher in applying silicate mineral treated nutrient solution to Komatsuna plants. Conclusion: Therefore, this nutrient solution treatment system can be expected to be applicable in nutri-culture and hydroponics.
\end{abstract}

Key words: Komatsuna, nutrient solution, nutrient film technique, silicate minerals

\section{INTRODUCTION}

High quality is more important than total yield in attaining competitiveness in modern horticulture. New technology for producing high quality vegetables with hydroponics can be used to improve water use efficiency, because it needs less of water compared to field cultivation for the same yield ${ }^{[1-3]}$. In hydroponics, the nutritional quality of a nutrient solution is limited by water quality ${ }^{[4]}$. In a nutri-culture system, the control of $\mathrm{pH}$ is important to plant growth. Nutri-culture system may be defined as a cultivation system of specific plants grown in nutrient solution hydroponically. In general, the $\mathrm{pH}$ value of nutrients ranges from 5.5-6.5, but varies because absorbed elements differ with stage of plant growth or kind of fertilizer.

The hydroponics culture can effectively carry out management of nutrient solution and stabilize the annual cultivation of crops. However, the quality of irrigation water such as groundwater, river and tap water are different by region and season. Therefore, it is not easy to control nutrient solution of irrigation water.
The problem lies in the control of nutrient solution for $\mathrm{pH}$, concentration of fertilizer and drainage after cultivation.

Development of new technology using very small energy of minerals is important in view of ecosystem agriculture. Silicate minerals such as quartz porphyry has been distinct for their enormous porosity, high absorption capacity and have ability of emitting natural minerals contained in the stone itself ${ }^{[5]}$. The physical and chemical properties of these minerals were expected in the activation of water in agriculture ${ }^{[6]}$. Some researchers have reported about effect of water quality on plant growth in the previous decade. There are reports that these can regulate $\mathrm{pH}$ and remove harmful pollutant in water while leaving important trace elements and minerals essential to life $\mathrm{e}^{[5]}$.

In this study, negative charge of silicate minerals using the water treatment system was tested and water treatment system with silicate minerals were directly installed in the tank of NFT hydroponics system (treatment section) in growing Komatsuna (Brassica rapa L. nothovar) plants.

Corresponding Author: Sheheli Islam, Laboratory of Biological and Environmental Systems, Faculty of Agriculture, Kochi University, Nankokushi, Monobe B200, Kochi 783-8502, Japan Tel/Fax: +81-88-864-5192 


\section{MATERIALS AND METHODS}

Silicate mineral samples: The silicate minerals used in the experiment were Quartz porphyry, Metamorphic rock and Sedimentary rock were collected from Shimanto layer, Shikoku island, Japan. Islam et al. ${ }^{[7]}$ have presented the main chemical compositions of these minerals. The mixed material was made by these minerals set into different mixture ratio as, Quartz porphyry: Metamorphic rock = 4:1 (Q4M1), Quartz porphyry: Metamorphic rock $=1: 1(\mathrm{QM})$, Quartz porphyry: Metamorphic rock = 7:3 (Q7M3) and Quartz porphyry: Metamorphic rock $=3: 2(\mathrm{Q} 3 \mathrm{M} 2)$. The sample names were QM, Q4M1, Q7M3, Q3M2 and Quartz porphyry: Q, metamorphic rock: M and control. Two type of sample were made by using same mixing ratio, one was made by mixing powder of these minerals and another type was prepared by using small stones at the size of $2 \mathrm{~mm} \sim 9 \mathrm{~mm}$ in diameter.

Similarly two sets of seven samples as QS, Q4S1, Q7S3, Q3S2 and Quartz porphyry: Q, sedimentary rock: $\mathrm{S}$ and control were prepared by following the same mixing ratio pattern by using Quartz porphyry and Sedimentary rock.

Plant materials: Komatsuna seeds were used in this experiment because these are quick growing leafy vegetables familiar in Japan and have relatively uniform root and hypocotyl growth.

Water treatment for germination test: Five gram of each sample was taken in $500 \mathrm{~mL}$ of tap water into the beaker and agitated for $1 \mathrm{~h}$ using a magnetic stirrer (MASUDA SM15C). Then the agitated water containing the minerals were centrifuged (KUBOTA 2010, $3000 \mathrm{rpm} 8 \mathrm{~min}$ ). The supernatant water samples were collected from the surface for analysis and for the germination of Komatsuna seeds.

Germination test: The germination tests were carried out in an incubator (SHIMADZU BITEC-400) with seeds of Komatsuna at $25^{\circ} \mathrm{C}$ by using all treated water and tap water (control). Twenty grains of the seeds (5X4) were embedded in the Petri dish (diameter $8 \mathrm{~cm}$ and height $3 \mathrm{~cm}$ ) on top of a filter paper (Whatman No41 , diameter $90 \mathrm{~mm}$ ). Five milliliter treated water of each sample was poured in each Petri dish. This experiment was conducted in triplicate. After 3 days of sowing, the root and shoot length of seedlings were measured.

Nutrient Treatment system: The treatment system in a 300-L RFP (rein-forced fiber plastic) nutrient tank consisted of a container of stainless steel, air pump and submerged pump (Fig. 1). Ten kilogram stones of silicate mineral mixtures (Quartz porphyry: Sedimentary rock: $4: 1$ ) with $2-9 \mathrm{~mm}$ particle size were placed inside the stainless steel layer of the container $\left(0.3 \mathrm{~m}^{3}\right.$ volume $)$. The nutrient solution was pumped into the layer through the submerged pump. Pressurized air was allowed to pass through the air pump at a flow rate of $0.035 \mathrm{~m}^{3} \mathrm{~min}^{-1}$ from the lower layer to the upper layer of the stainless steel container.

Nutrient Film Technique (NFT) system: The way NFT works is fairly simple-it provides a slowly moving stream of nutrient solution (referred to as a film) to the roots of plants which are immersed in sloped channels. The Schematic diagram of NFT hydroponics system is shown in Fig. 2. The NFT growing system took place on a flat surface, much like a table, with a series of 1 millimeter to 3 millimeter deep gullies, running lengthwise across its surface. It was about $0.9 \mathrm{~m}$ high, $11 \mathrm{~m}$ length, $0.6 \mathrm{~m}$ width, channel number 5 and it was set at $1 / 80$ gradients. The nutrient solution stream was then fed to the plants via a submersible pump at the flow rate of $6 \mathrm{~L} \mathrm{~min}{ }^{-1}$. The nutrient solution was prepared by using the prescribed nutrients referred as Otsuka House No. 1 and 2 so that $\mathrm{pH}$ of nutrient solution ranged around 5.0-7.0 and EC ranged from 2.5-3.0 dS m $\mathrm{d}^{-1}$.

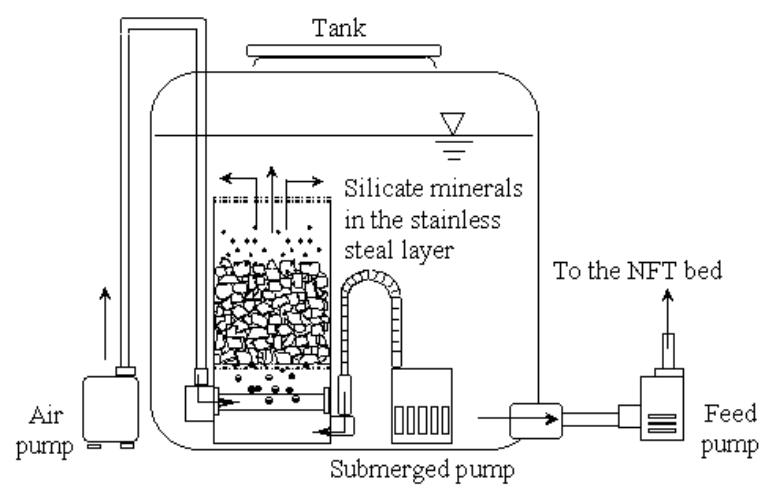

Fig. 1: Nutrient solution treatment system

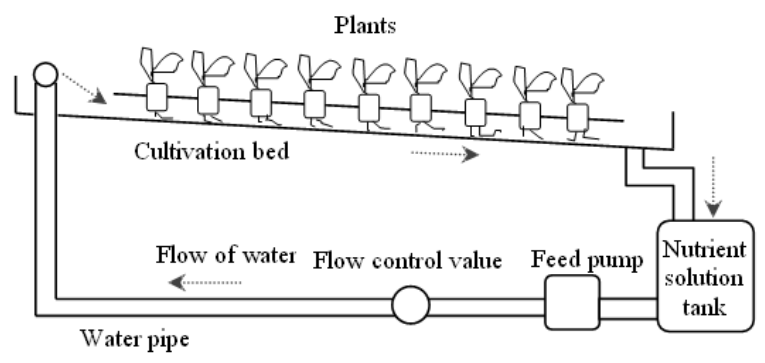

Fig. 2 NFT hydroponics system 
The pump released nutrient solution at one end of the table causing the stream to spread evenly to each channel, flowing downward and submersing each plant in approximately 1-3 $\mathrm{mm}$ of nutrient-rich water. Once the stream reached the end of the table it was caught at the bottom of the tank and then re-circulated. A liquid level sensor and magnetic valve controls the water in the tank.

The experimental design for NFT involved two groups, one treatment group and one control. For the control set-up, there was no use of silicate minerals; tap water with nutrient solution was used for growing seedlings. For the treatment set-up, silicate mineral treated nutrient solution was applied for growing seedlings. Acidity $(\mathrm{pH})$ and $\mathrm{EC}$ of both nutrient solutions were recorded every day at a particular time.

In cultivating Komatsuna, seeds were germinated in urethane cube at $25^{\circ} \mathrm{C}$ on 9 th November 2007 . Then, after a 12-day germination period, seedlings $(1 \mathrm{~cm})$ were transplanted to nursery boxes divided into two NFT bed receiving the intended nutrient solution (control or treated solution). For each experimental group, there were 10 nursery boxes containing 50 pores, made of Styrofoam and placed on the NFT cultivation bed in the greenhouse. The roots of each Komatsuna plant were fixed in a root cube and placed in pores of Styrofoam within the gullies. Komatsuna plants were harvested at 5 weeks old of seedlings age after transplantation.

Growth of plants: After harvest of Komatsuna vegetable, 120 plants (12 plants from each box) were picked randomly as samples for each treatment. The plant length, leaf width and fresh weight of plants were measured. In addition, the comparison of growth rate between control and treatment were analyzed.

Mineral content: Twenty four representative plants of each section were analyzed for evaluating the inner mineral content. At the end of the growing period, these plants were harvested, weighed and were dried in an oven (SA460) at $70^{\circ} \mathrm{C}$ until constant weight was reached and subsequently ground to powder. The concentration of $\mathrm{Ca}, \mathrm{K}$ and $\mathrm{Mg}$ was determined on dry basis by atomic absorption spectrophotometry (SFP3, Fujihara Industry Co. Ltd.).

Vitamin C: Edible parts of Komatsuna vegetables were chopped into small size by a kitchen knife and then $30 \mathrm{~g}$ of the sample was homogenized with $80 \mathrm{~mL}$ of $5 \%$ Meta phosphoric acid. $6 \mathrm{~g}$ of the extract was then taken in a $50 \mathrm{~mL}$ volumetric flask and was made up to the mark by adding 2\% Meta phosphoric acid. This solution was then filtered and stored in vial for HPLC analysis. High Performance Liquid Chromatography (HPLC) separations were performed on reversed phase C18 column (of $15 \mathrm{~cm} \times 4.6 \mathrm{~mm}$ i.d., particle size 5 micron) using a Waters 600E high performance liquid chromatograph equipped with a variable length UV/Visible detector (Waters 2487). The samples were injected manually by using Rheodyne injector. HPLC working conditions were binary gradient, eluent was (1\% TFA: water) and flow rate $1.4 \mathrm{~mL} 1 \mathrm{~min}^{-1}$ and injection volume was $20 \mu \mathrm{L}$. Vitamin $\mathrm{C}$ present in the samples were identified by comparing its retention time with that of a standard $(2.54 \mathrm{~min})$. The quantitative determination was carried out by comparing the peak area of vitamin $\mathrm{C}$ in the sample extract with the peak area of the injected standard solution in the obtained calibration curve.

Statistical analysis: Average and standard deviation of data for each parameter were computed. Data from each experiment were analyzed separately by using analysis of variance (ANOVAs) procedures and the least significant differences $(\mathrm{p}=0.05, \mathrm{p}=0.01)$ were calculated for parameters exhibiting a significant growth of Komatsuna from its control.

\section{RESULTS}

Comparison of seedling length: Komatsuna seeds were exposed to the treated water for three days. After germination root length and shoot length were measured to know the effect of treatments on plant growth. Average values of root and shoot lengths were compared with the seedlings receiving treated and control water. Table 1 and 2 shows that, there was slight difference in plant height, in all treatments, however, Komatsuna seedlings grown in Q4M1 treated water showed a significant difference from control.

Growth of seedlings was greatly influenced by the addition of silicate minerals in water. The highest seedling length $(54.3 \mathrm{~mm})$ was in Q4S1 treatment. Significant increase of growth at $5 \%$ level was observed for both Powder and stone form. The value $200-300 \mathrm{mV}$ for ORP and $\mathrm{pH}$ 5.5-7.5 is accepted for well growth of plants in agriculture according to the results of ${ }^{[8]}$.

Physical properties of nutrient solution: The values of $\mathrm{pH}$ and $\mathrm{EC}$ of circulated nutrient solution from the FRP nutrient tank were measured at a fixed time at every $24 \mathrm{~h}$ of interval in each day during the whole cultivation period of Komatsuna plants. Figure 3 and 4 shows the comparison of these values in between treatment and control at various cultivation days. 
Am. J. Agri. \& Biol. Sci., 4 (1): 12-17, 2009

Table 1: Comparison of average seedling length using different treatments prepared from Quartz porphyry and metamorphic rock for Komatsuna

\begin{tabular}{lllll}
\hline & \multicolumn{2}{c}{ Powder } & \multicolumn{2}{c}{ Stone } \\
& $\begin{array}{l}\text { Root } \\
\text { length } \\
(\mathrm{mm})\end{array}$ & $\begin{array}{l}\text { Shoot } \\
\text { length } \\
(\mathrm{mm})\end{array}$ & $\begin{array}{l}\text { Root } \\
\text { length } \\
(\mathrm{mm})\end{array}$ & $\begin{array}{l}\text { Shoot } \\
\text { length } \\
(\mathrm{mm})\end{array}$ \\
\hline $\mathrm{Q}$ & $41.7 \mathrm{a}(10.7)$ & $16.6(4.4)$ & $50.0 \mathrm{a}(8.7)$ & $18.5(4.3)$ \\
$\mathrm{M}$ & $47.0 \mathrm{~b}(10.9)$ & $18.2(4.2)$ & $48.4 \mathrm{a}(10.7)$ & $18.2(4.9)$ \\
$\mathrm{QM}$ & $41.6 \mathrm{a}(8.6)$ & $17.0(5.1)$ & $42.7 \mathrm{~b}(11.5)$ & $17.7(4.4)$ \\
$\mathrm{Q} 4 \mathrm{M} 1$ & $47.0 \mathrm{~b}(10.1)$ & $18.1(4.7)$ & $48.7 \mathrm{a}(9.3)$ & $18.6(4.4)$ \\
Q7M3 & $45.9 \mathrm{bc}(9.8)$ & $18.7(5.0)$ & $42.7 \mathrm{~b}(11.5)$ & $17.7(4.4)$ \\
Q3M2 & $43.1 \mathrm{ac}(8.5)$ & $18.5(5.6)$ & $48.7 \mathrm{a}(9.3)$ & $18.6(4.4)$ \\
Control & $42.5 \mathrm{a}(8.7)$ & $18.2(3.8)$ & $43.4 \mathrm{~b}(10.5)$ & $18.6(4.7)$ \\
\hline Means (60 & samples) within the same column followed by identical \\
small letters are not significantly different from each other according
\end{tabular}

Table 2: Comparison of average seedling length using different treatments prepared from Quartz porphyry and sedimentary rock for Komatsuna

\begin{tabular}{lllll}
\hline & \multicolumn{2}{c}{ Powder } & \multicolumn{2}{c}{ Stone } \\
& $\begin{array}{l}\text { Root } \\
\text { length } \\
(\mathrm{mm})\end{array}$ & $\begin{array}{l}\text { Shoot } \\
\text { length } \\
(\mathrm{mm})\end{array}$ & $\begin{array}{l}\text { Root } \\
\text { length } \\
(\mathrm{mm})\end{array}$ & $\begin{array}{l}\text { Shoot } \\
\text { length } \\
(\mathrm{mm})\end{array}$ \\
\hline Q & $42.6 \mathrm{a}(12.0)$ & $19.5 \mathrm{a}(5.5)$ & $50.0 \mathrm{a}(10.5)$ & $19.4(4.6)$ \\
S & $45.4 \mathrm{~b}(11.2)$ & $21.7 \mathrm{a}(6.1)$ & $46.4 \mathrm{bc}(10.0)$ & $20.5(4.5)$ \\
QS & $42.1 \mathrm{a}(9.5)$ & $18.5 \mathrm{~b}(4.2)$ & $45.2 \mathrm{bd}(9.9)$ & $18.1(5.0)$ \\
Q4S1 & $51.4 \mathrm{c}(9.6)$ & $20.4 \mathrm{a}(5.6)$ & $54.3 \mathrm{a}(10.4)$ & $20.4(5.5)$ \\
Q7S3 & $40.6 \mathrm{a}(10.8)$ & $20.6 \mathrm{a}(5.5)$ & $47.0 \mathrm{bc}(11.9)$ & $19.8(4.7)$ \\
Q3S2 & $44.5 \mathrm{~b}(10.2)$ & $20.7 \mathrm{a}(5.0)$ & $49.3 \mathrm{a}(8.5)$ & $19.8(4.5)$ \\
Control & $42.1 \mathrm{a}(9.4)$ & $17.5 \mathrm{~b}(4.9)$ & $44.4 \mathrm{bd}(10.5)$ & $20.0(5.0)$ \\
\hline Means
\end{tabular}

Means (60 samples) within the same column followed by identical small letters are not significantly different from each other according to Duncun's multiple range test at $5 \%$ and followed by same capital letters are significantly different from each other at $1 \%$ level

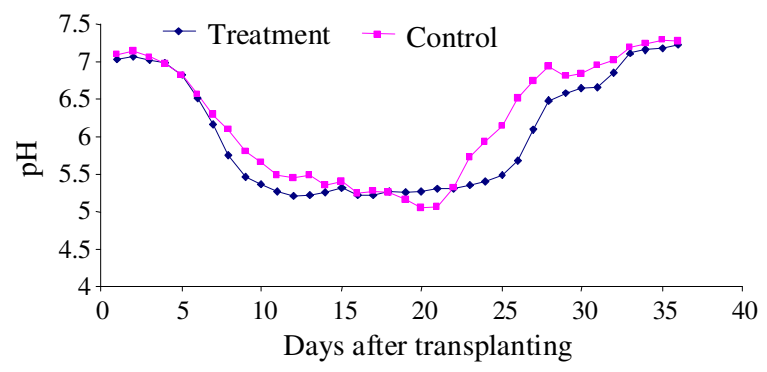

Fig. 3: Changes in $\mathrm{pH}$ values between control and treatment at different days of Komatsuna cultivation

In the case of $\mathrm{pH}$ in Fig. 3, the $\mathrm{pH}$ decreased anomalously and largely at control in the initial days of experiment, while $\mathrm{pH}$ were not changed significantly in the same days at test and then decreased linearly. After certain days, when the additional nutrient solution was added to both circulated nutrient water solutions as

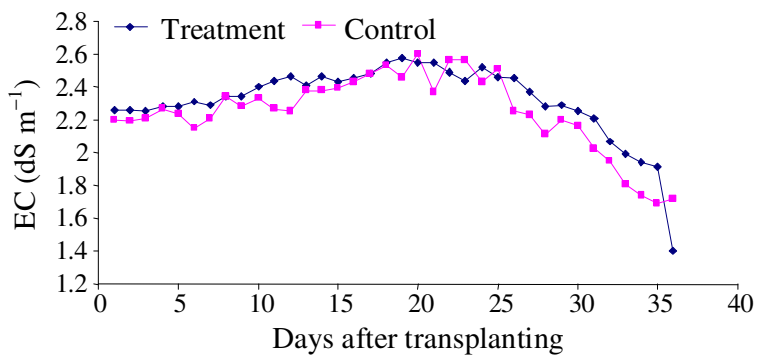

Fig. 4: Changes in EC values between control and treatment at different days of Komatsuna cultivation

replenishment into the FRP tanks, $\mathrm{pH}$ rose in both control and test solution in the first few days and then began to decrease again. In each case due to the addition of nutrient solution to the tank, the same phenomenon was observed. The $\mathrm{pH}$ remained at the range between 5.05-7.2 at control and 5.2-7.1 at treatment in the whole cultivation procedure of Komatsuna plants. The ratio in uptake of anions (negatively charged nutrients) and cations (positively charged nutrients) by plants may cause substantial shifts in $\mathrm{pH}$. In general, an excess of cation over anion leads to a decrease in $\mathrm{pH}$, whereas an excess of anion over cation uptake leads to an increase in $\mathrm{pH}$. As nitrogen may be supplied either as a cation (ammonium- $\mathrm{NH}_{4}{ }^{+}$) or an anion (nitrate- $\mathrm{NO}_{3}{ }^{-}$), the ratio of these two forms of nitrogen in the nutrient solution can have large effects on both the rate and direction of $\mathrm{pH}$ changes with time.

Electrical Conductivity (EC) was increased linearly in each of passing days at control and treatment (Fig. 4). During and after the replenishment of nutrient solution into the tanks, the EC values decreased gradually in both cases.

Growth of Komatsuna: Figure 5 and 6 show the plant length and leaf width of Komatsuna plants. There was no significant difference in growth of plants grown in control and treated water. However, it was notified that, at the beginning stage the growth rate of plant in control section $\left(12.6 \mathrm{~mm} \mathrm{day}^{-1}\right)$ was more compared to treatment $\left(10.7 \mathrm{~mm} \mathrm{day}^{-1}\right)$. But after 4 weeks plants showed a growth rate of $15.9 \mathrm{~mm} \mathrm{day}^{-1}$ in the treatment section and $15.1 \mathrm{~mm} \mathrm{day}^{-1}$ in the control section. Before harvesting, it grew $16.16 \mathrm{~mm} \mathrm{day}^{-1}$ in control section and $17.33 \mathrm{~mm} \mathrm{day}{ }^{-1}$ in treatment section. Therefore, 2-3 days were needed for the treatment section (296.6 mm leaf length) to reach the leaf length of the control section $(308.9 \mathrm{~mm})$. In other words, late harvest for 2 or 3 days seems to be needed using treated water. 
Am. J. Agri. \& Biol. Sci., 4 (1): 12-17, 2009

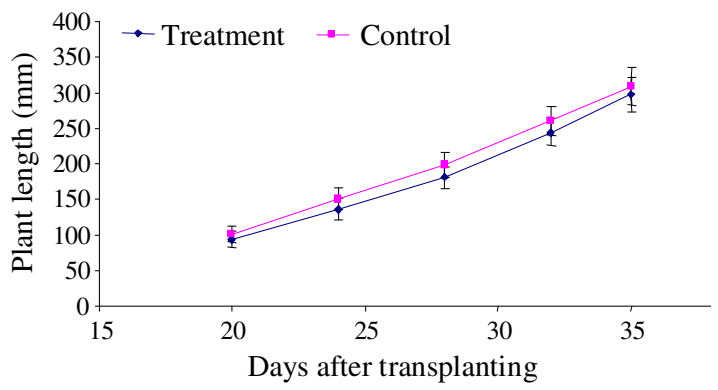

Fig. 5: Changes in leaf length between control and treatment at different days of Komatsuna cultivation

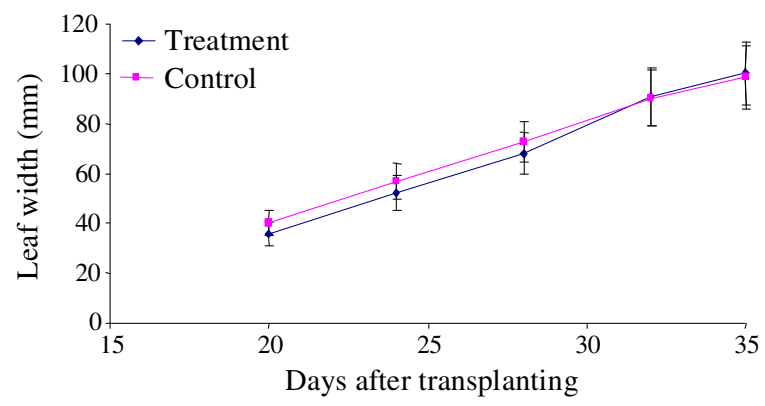

Fig. 6: Changes in leaf width between control and treatment at different days of Komatsuna cultivation

Table 3: The effects of silicate mineral treatment on fresh weight, dry weight, moisture content and chlorophyll index of Komatsuna plants

\begin{tabular}{lllll}
\hline & $\begin{array}{l}\text { Fresh } \\
\text { Weight } \\
(\mathrm{g})\end{array}$ & $\begin{array}{l}\text { Dry matter } \\
\text { content } \\
(\%)\end{array}$ & $\begin{array}{l}\text { Moisture } \\
\text { Content } \\
(\%)\end{array}$ & SPAD \\
\hline Control & $37.1 *(9.4)$ & $4.2(0.3)$ & $95.78(10.1)$ & $36.1(1.9)$ \\
Treatment & $33.8(9.6)$ & $4.4(0.1)$ & $95.62(11.5)$ & $37.1^{* *}(2.9)$ \\
\hline$* *:$ Significant different according to Duncan's multiple range test at \\
$\mathrm{p}=0.01 ; *$ : Significant different according to Duncan's multiple \\
range test at $\mathrm{p}=0.05$
\end{tabular}

However, it was found that width of leaves were less in treatment section for the first 4 weeks, but after that leaves started growing wider in treated water (Fig. 6).

Quality of Komatsuna: Table 3 shows the quality of Komatsuna vegetables. In comparison, the fresh weight after harvesting, Komatsuna grew heavier in control section. In the treatment section, the plants grew 9\% less heavily than control. Where as dry matter content is more in treatment section. Also, it was found that SPAD value was significantly improved by using treated water.
Table 4: Mineral contents of Komatsuna plant in control and treatment

\begin{tabular}{lllll}
\hline & $\begin{array}{l}\mathrm{K} \\
(\% \mathrm{DW})\end{array}$ & $\begin{array}{l}\mathrm{Ca} \\
(\% \mathrm{DW})\end{array}$ & $\begin{array}{l}\mathrm{Mg} \\
(\% \mathrm{DW})\end{array}$ & $\begin{array}{l}\text { Vitamin C } \\
\left(\mathrm{mg} 100^{-1} \mathrm{~g} \mathrm{FW}\right)\end{array}$ \\
\hline Control & $7.85(0.42)$ & $3.17(0.9)$ & $0.41(0.06)$ & $41.4(5.3)$ \\
Treatment & $8.66^{* *}(0.18)$ & $3.00(0.6)$ & $0.49(0.02)$ & $40.9(10.6)$ \\
\hline **: Significant different according to Duncan's multiple range test at \\
$\mathrm{p}=0.01 ; *:$ Significant & different according to Duncan's multiple \\
range test at $\mathrm{p}=0.05$
\end{tabular}

Table 4 showed that the inner mineral content of treated Komatsuna was improved compared to control. It is found that the amount of $\mathrm{K}$ and $\mathrm{Mg}$ were more in treated plant where as amount of $\mathrm{Ca}$ and vitamin $\mathrm{C}$ was present in almost similar amount on both control and treatment section.

\section{DISCUSSION}

It is important to raise the function of water since water quality is different by region and by season. The quality of irrigation water is largely related to the management of nutrient solution in hydroponics culture and in the growth of plant. Plant growth is related to nutrient $\mathrm{pH}$ and nutrient components. The use of silicate minerals, which caused a buffering of $\mathrm{pH}$ with additional negative charges, was considered in development of a buffer nutrient system and a nutriculture system using silicate minerals. The average seedling growth of Komatsuna applying different treated waters with mixture of any two silicate minerals showed better improvement of seedling growth than the others. Significant increase of growth at 5\% level was observed for Q4S1 compared to control. Though inferior growth of Komatsuna plants were observed, but quality of vegetables i.e., freshness and dry contents were improved and also inner mineral contents of Komatsuna $(\mathrm{K}, \mathrm{Mg})$ were found higher in applying silicate mineral treated nutrient to Komatsuna plants. From the ion analysis of nutrient solution it was observed that the amounts of ion components (anion and cation) are more in treatment section than the control, providing evidences for respective ion liquation from the mixtures of silicate minerals. The nonessential and the essential ions that are in excess to what the plants uptake, tend to accumulate in the system. When the nutrient solution is recycled, several ions may accumulate in the nutrient solution by reducing salt solubility and can causes nutrient imbalances affecting both crop yield and quality. So, despite of the fact that, this mixture of two silicate minerals can improve early growth of plant, it can not improve yield of Komatsuna plant due to disruption in 
the nutrient solution. Still this treatment system could be used as it is advantageous in controlling the growth of seedlings and improving quality of vegetables.

\section{CONCLUSION}

The results seem to give clear perspectives to obtain good quality vegetables by using silicate minerals treated nutrient solution. In the future, because of water saving and environmental protection, use of closed soilless systems with re-circulating water will be indispensible. Therefore, use of silicate materials to produce a buffer nutrient system can alleviate deleterious effects of nutrient imbalances in recirculating systems.

\section{ACKNOWLEDGEMENT}

This project was accomplished with the financial support of President Fund from Kochi University in 2007.

\section{REFERENCES}

1. Rouphael, Y., G. Colla, A. Battistelli, S. Moscatello, S. Proietti and E. Rea, 2004. Yield, water requirement, nutrient uptake and fruit quality of zucchini squash grown in soil and closed soilless culture. J. Hortic. Sci. Biotechnol., 79: 423-430. http://www.jhortscib.org/Vol79/79_3/14.htm

2. Schnitzler, W.H., L. Trüggelmann, A. Toth, M. Woitke, Y. Tüzel, H. Tüzel, A. Hanafi, F. Jaquet, P. Le Grusse, H. Junge, F. Giuffrida, C. Leonardi, M.M. Wadid Awad, El-Behairy, F. Fort, J.M. Codron and M.M. Qaryouti, 2003. Efficient water use for high quality vegetables through the environmentally sound hydroponic production 'ECOPONICS'. Acta Hortic., 609: 493-495.

http://www.actahort.org/books/609/609_76.htm
3. Bradley, P. and C. Marulanda, 2000. Simplified hydroponics to reduce global hunger. Acta Hortic., 554: 289-295. http://www.actahort.org/books/554/554_31.htm

4. Tesi, R., A. Lenzi and P. Lombardi, 2003. Effect of salinity and oxygen level on lettuce grown in a floating system. Acta Hortic., 609: 383-386. http://www.actahort.org/books/609/609_58.htm

5. Ablaza, E. C., K. Ishikawa and T. Yoshimura, 2006. Effects of quartz porphyry (Bakuhan-seki) on soil quality and grain yield of wheat (Triticum aestivum L.). J. Food Agric. Environ., 4: 270-275. http://www.worldfood.net/scientficjournal/2006/issue 1/abstracts/ab stract56.php

6. Ishikawa, K., Y. Okada and H. Nakamura, 1995. Physical and chemical properties of Bakuhan-seki (Japanese text with English abstract). J. Jap. Soc. Agric. Mach., 57: 51-56.

http://www.fao.org/agris/search/display.do?f=./199 7/v2322/JP9602512.xml;JP9602512

7. Islam, S., N. Takeda, K. Ishikawa and M.A.K. Azad, 2008. Water treatment with silicate minerals and its effect on early growth of radish plant (Raphanus sativus L.). J. Food Agric. Environ., 6: 177-181. http://www.worldfood.net/scientficjournal/2008/issue1/abstracts/abst ract35.php

8. Azad, A.K., K. Ishikawa and N. Islam, 2004. Some physical characteristics of water and their influence on early growth in komatsuna (Brassica rapa $\mathrm{L}$. Nothovar) seedlings. Acta Hortic., 659: 613-620. http://www.actahort.org/books/659/659_79.htm 